\title{
Review
}

\section{The physiological role of drug transporters}

\author{
Yu Liang ${ }^{1}$, Siqi $\mathrm{Li}^{1}$, Ligong Chen ${ }^{1,2 \bowtie}$ \\ ${ }^{1}$ Department of Pharmacology and Pharmaceutical Sciences, School of Medicine, Tsinghua University, Beijing 100084, China \\ 2 Collaborative Innovation Center for Biotherapy, State Key Laboratory of Biotherapy and Cancer Center, West China Hospital, \\ West China Medical School, Sichuan University, Chengdu 610041, China \\ $\triangle$ Correspondence: ligongchen@biomed.tsinghua.edu.cn (L. Chen) \\ Received January 2, 2015 Accepted February 15, 2015
}

\begin{abstract}
Transporters comprise the largest family of membrane proteins in human organism, including members of solute carrier transporter and ATP-binding cassette transporter families. They play pivotal roles in the absorption, distribution and excretion of xenobiotic and endogenous molecules. Transporters are widely expressed in various human tissues and are routinely evaluated during the process of drug development and approval. Over the past decade, increasing evidence shows that drug transporters are important in both normal physiology and disease. Currently, transporters are utilized as therapeutic targets to treat numerous diseases such as diabetes, major depression, hypertension and constipation. Despite the steady growth of the field of transporter biology, more than half of the members in transporter superfamily have little information available about their endogenous substrate(s) or physiological functions. This review outlines current research methods in transporter studies, and summarizes the drug-transporter interactions including drug-drug and drug-endogenous substrate interactions. In the end, we also discuss the therapeutic perspective of transporters based on their physiological and pathophysiological roles.
\end{abstract}

KEYWORDS transporter, physiological role, therapeutic implication

\section{INTRODUCTION}

Movement of many drugs and endogenous molecules across the cell membrane is governed by protein transporters. In general, membrane transporters are divided into two major superfamilies - the ATP binding cassette (ABC) family and the solute carrier (SLC) family. To date, more than 400 transporters have been annotated in the human genome. The $A B C$ transporters are primary active transporters that utilize the energy from ATP hydrolysis to transport substrates across the membrane. SLCs can be either facilitative transporters, which transport their substrates down the gradient across the membrane, or secondary active transporters, which transport their substrates against the gradient across the membrane by coupling a downhill transport of another substrate. Major drug transporters are listed in Table 1 together with their relevant abundance among human tissues, physiological roles, endogenous and exogenous substrates, and related pathologies.

The biological function of transporters has been investigated using multiple approaches. Among them, metabolomic studies have been quite valuable for substrate identification of transporters systemically, which identify the alterations of many metabolites or their substrates directly. Alternatively, the uptake of substrate candidates can be evaluated by radio-tracer or radio-free LC/MS quantification. This method was used to identify thiamine and ergothioneine as the physiological substrates of OCT1 (SLC22A1) and OCTN1 (SLC22A4) respectively (Chen et al., 2014; Gründemann et al., 2005). Clinically, genome-wide association studies (GWASs) have proved a powerful method for identifying disease susceptibility genes. GWASs indicate that genes coding for a variety of transporters are susceptibility genes for many diseases (Gottesman and Ambudkar, 2001; Stefková et al., 2004; Grisanzio et al., 2012; Suhre et al., 2011; Diabetes Genetics Initiative et al., 2007), suggesting that transporters have important physiological/pathophysiological roles in disease. The function of transporters in drug ADME (absorption, distribution, metabolism and excretion) has been intensively studied during the past two decades but their physiological roles have been much under studied. There is emerging evidence that understanding the physiological roles of transporters in normal as well as pathophysiological conditions is of great value for the development of new drugs and therapies (the International Transporter Consortium et al., 2010; Mizuno et al., 2003). In this review, 

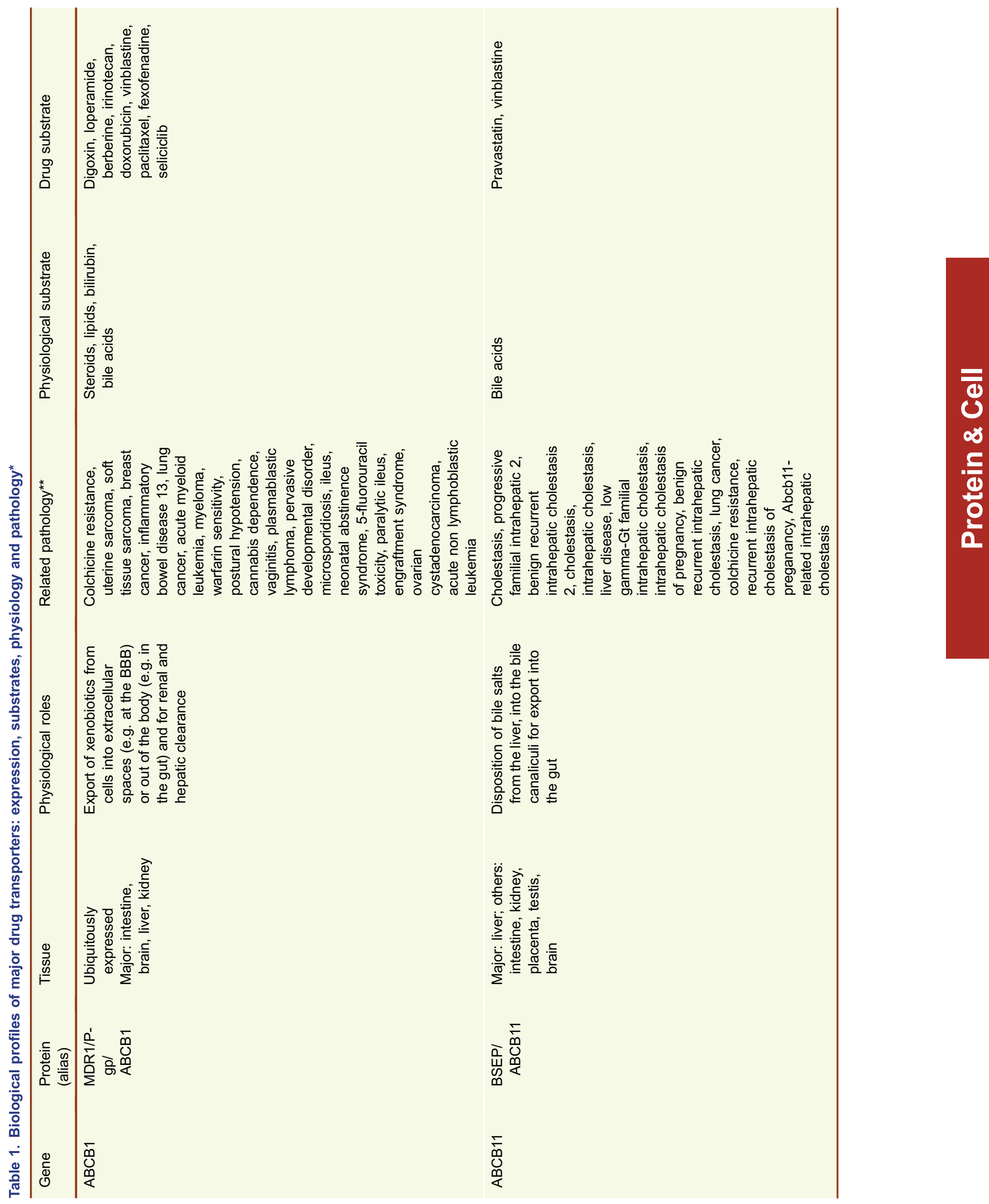


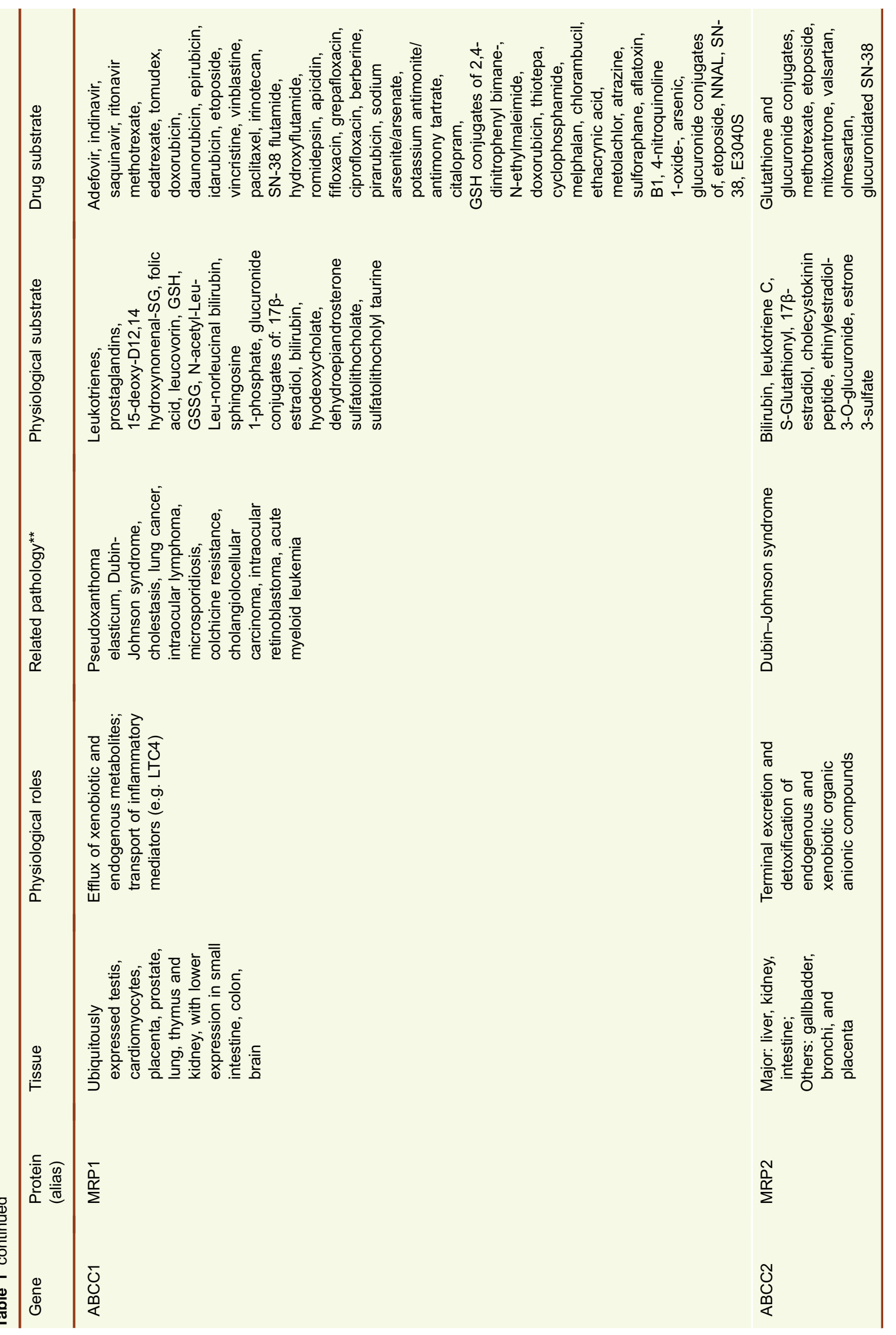




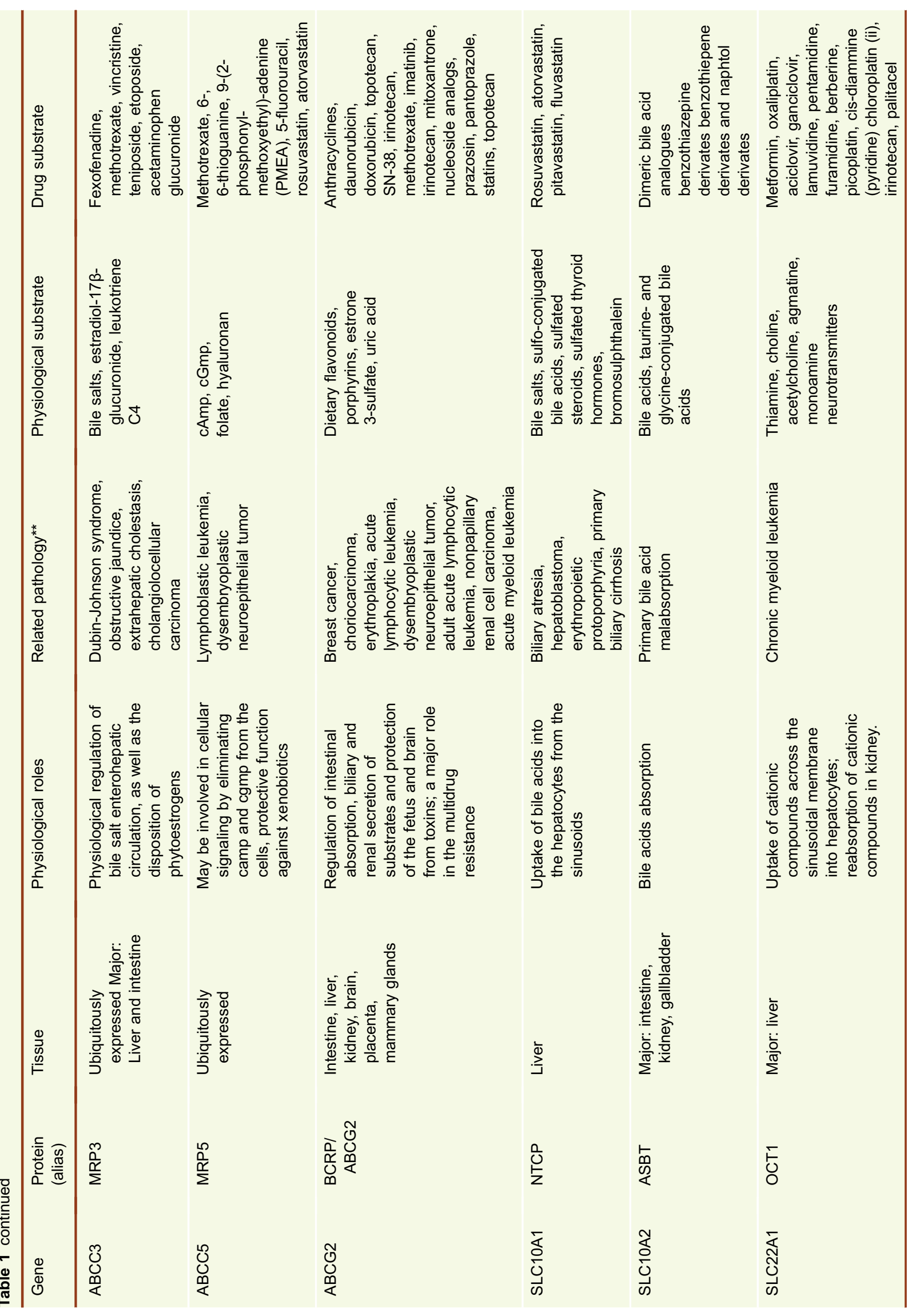




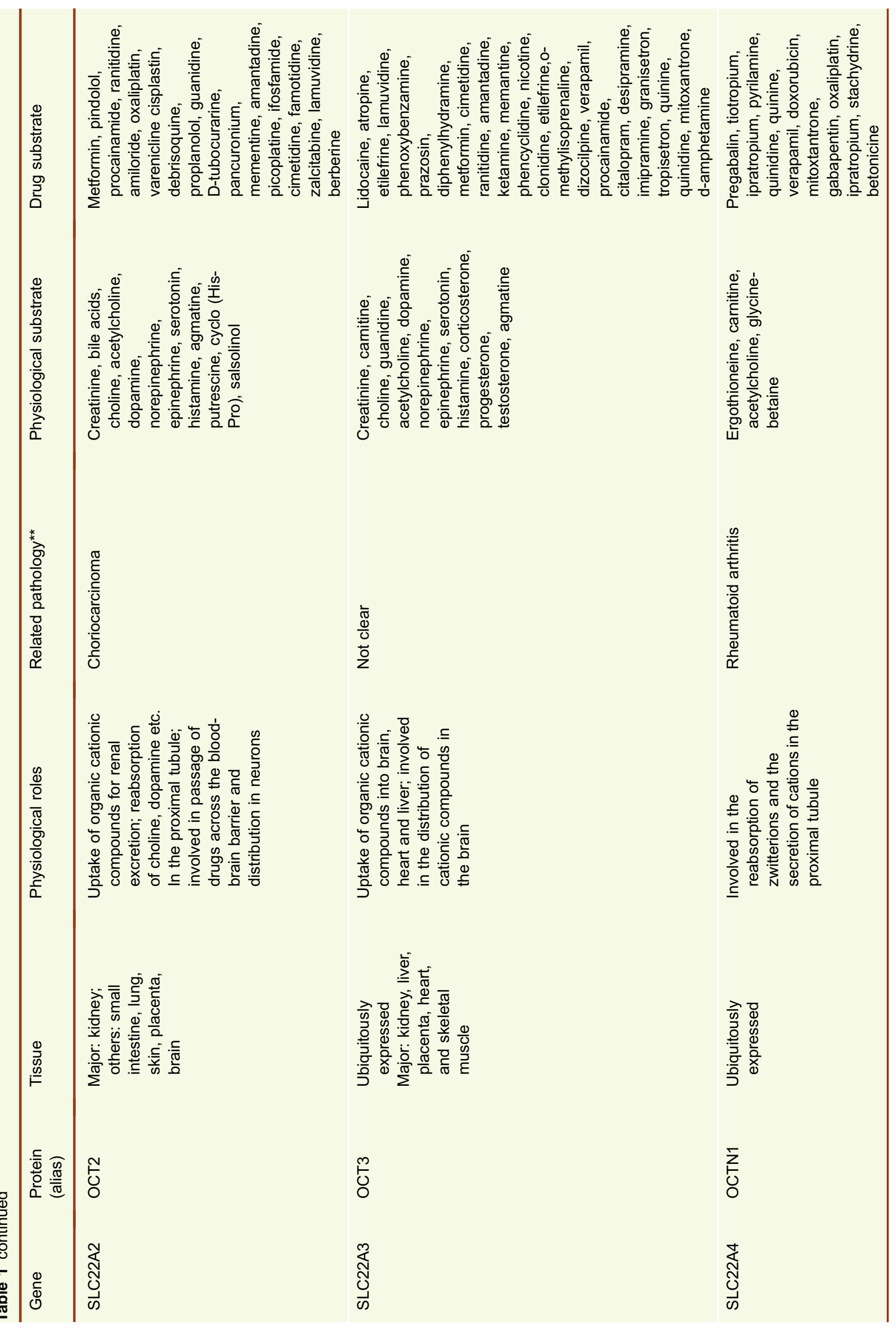




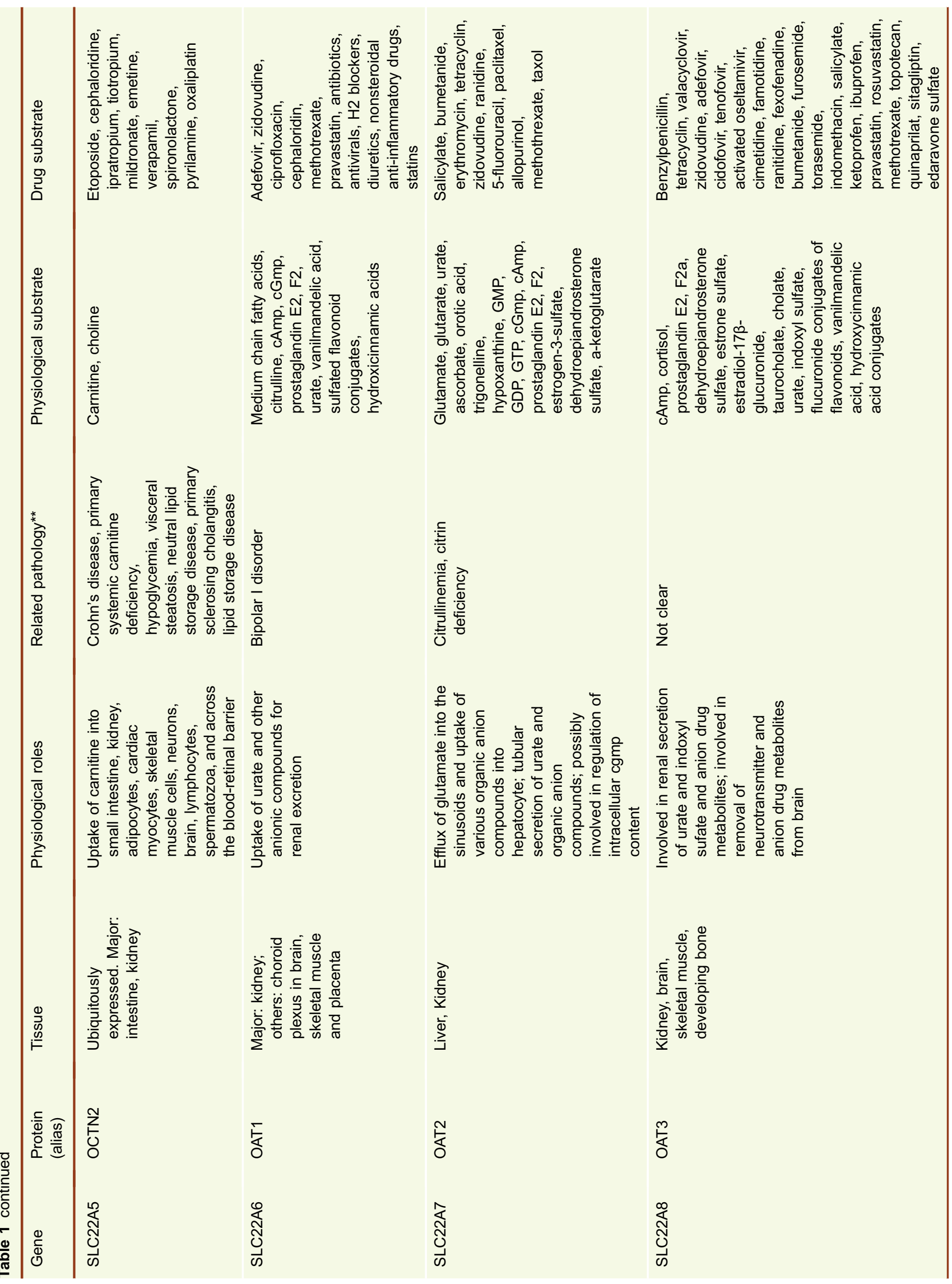




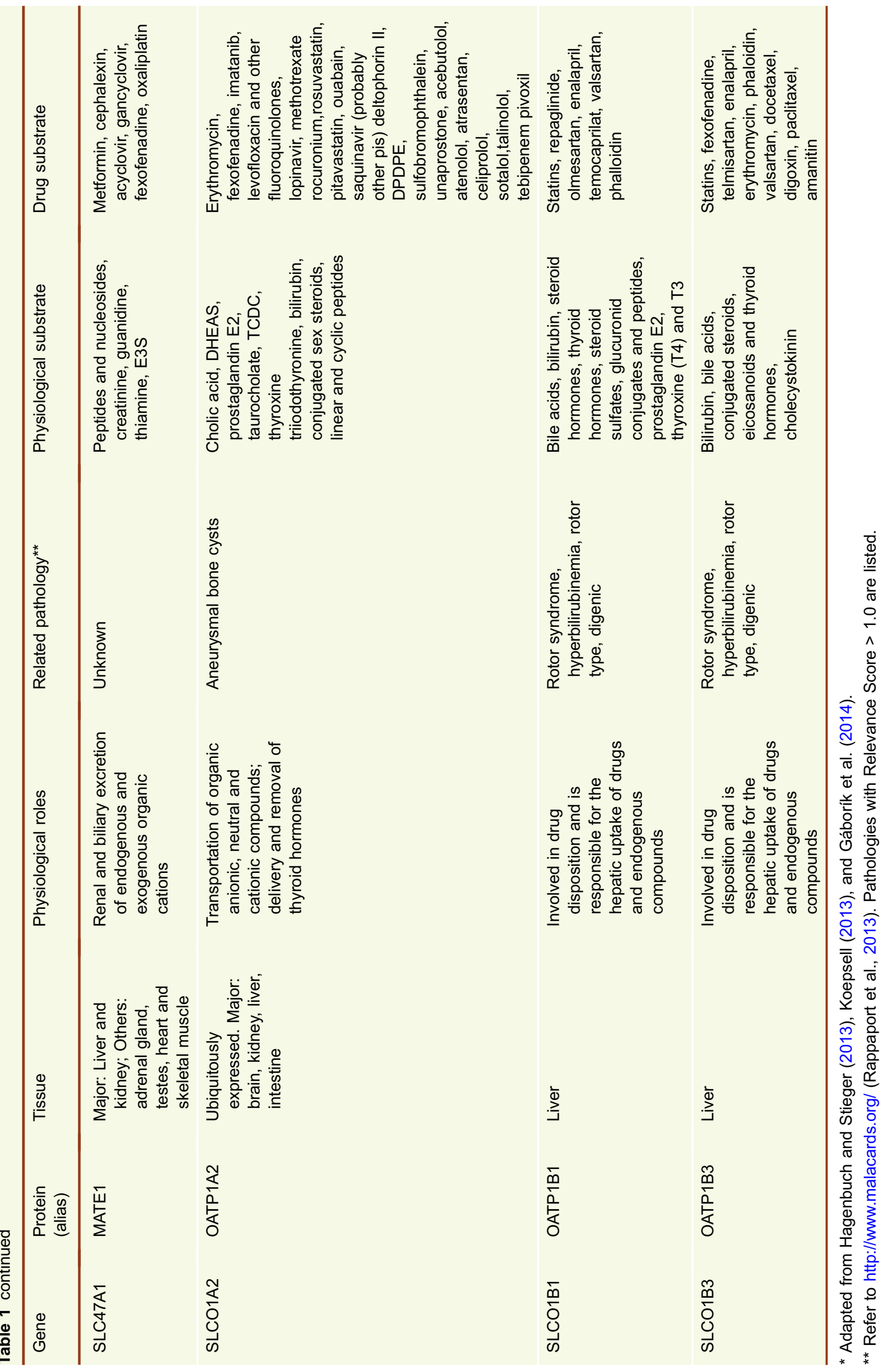


we summarize recent progress in the study of physiological roles of transporters, including new methodology in transporter biology, drug-drug interaction (DDI) and drug-endogenous substrate interaction. Finally, we discuss pharmaceutical implications of transporters using the roles of transporters in metabolic diseases as examples.

\section{CURRENT RESEARCH TRENDS IN TRANSPORTER STUDY}

With the rapid progress of biomedical technologies, methods for studying membrane transporters have expanded extensively. Generally, transporter research methods are performed using bottom-up or top-down approaches. The topdown approach utilizes computational biology or crystal structure analyses of transporter structure, which provides insight into the binding site, binding affinity prediction and the potential conformational change of the transporter upon substrate binding. Using this information, predicted agonists or antagonists for the transporter can be validated via in vitro transporter assays. The bottom-up approach uses discovery metabolomics, cell culture and animal models, GWAS or other genomics data as well as metabolism pathways to identify substrate candidates for specific transporters. In this section, we mainly discuss current trends in methods for studying membrane transporters.

\section{Structure-based computational biology}

Research progress in ligand-protein interaction has been greatly aided by advances in structural biology, most notably X-ray crystallography, NMR spectroscopy and electron microscopy. In particular, computational modeling and virtual screening of small molecule libraries based on structural biology have accelerated the identification of substrates and drug candidates of transporters. Although there are only a few human SLC transporters whose atomic structures have been determined [e.g. the Rhesus glycoprotein ammonium transporter SLC42A3 (Gruswitz et al., 2010) and the glucose transporter SLC2A1 (Deng et al., 2014)], several highresolution structures of proteins from prokaryotic and other eukaryotic organisms are available with at least $25 \%$ sequence identity with human homologues (Gao et al., 2009; Fang et al., 2009; Shaffer et al., 2009; Lu et al., 2011). Substrate prediction and virtual screening of drug candidates become possible with computational modeling and docking based on the available structural information. For example, novel ligands have been successfully screened from compound libraries for the norepinephrine transporter (NET, SLC6A2, Schlessinger et al., 2011), the GABA transporter 2 (GAT-2, SLC6A13, Schlessinger et al., 2012), and the largeneutral amino acid transporter (LAT-1, SLC7A5, Geier et al., 2013), based on the crystal structures of their prokaryotic homologues. Ligand discovery can also be accomplished by ligand-based modeling. For example, Wittwer et al. developed a quantitative structure-activity relationship (QSAR) model of ligand binding to the multidrug and toxin extrusion transporter 1 (MATE1, SLC47A1) by experimental highthroughput screening (HTS) for drug libraries. After refinement by low-throughput experiment validation, the performance of the model was improved. The refined model was then applied to the screening of compound libraries in order to find novel ligands binding to MATE1 (Wittwer et al., 2013). With the number of resolved membrane transporter structures increasing and the development of computational tools, in silico analysis are expected to greatly facilitate substrate or inhibitor discovery in transporter study.

\section{Clinical genomics}

The complexity of human genetics provides a rich resource to investigate the potential roles of drug transporters in physiological and pathophysiological conditions. Human diseases linked to genetic variances, including polymorphisms, insertions and deletions, in transporter genes provide insight into their physiological roles. For example, ABCG2 was identified as a renal proximal tubular urate efflux transporter when a GWAS showed that SNPs in ABCG2 were correlated with altered serum urate levels and gout (Woodward et al., 2009). Further work confirmed that ABCG2 was a high capacity urate exporter involved in serum urate homeostasis (Nakayama et al., 2011). Many transporters have multi-specificity towards numerous substrates thus the clinical outcomes for transporters like aforementioned ABCG2 may reflect only a portion of their physiological function (Table 1). Mutations in genes that encode transporter proteins have also been associated with a variety of human diseases (as shown in Table 1 for drug transporters). For example, genetic defects in glucose transporters like GLUT1 (SLC2A1) have been associated with glucose-galactose malabsorption (Pascual et al., 2004). Mutations in anion transporter SLC26 genes are associated with congenital or early onset Mendelian diseases like chondrodysplasias, chloride diarrhea and deafness with enlargement of the vestibular aqueduct (Alper and Sharma, 2013). On the flip side, the identification of genetic variants in transporter genes with protective or beneficial effects provides substantial therapeutic targets in clinical application. An example of this is the zinc transporter ZnT8 (see discussion in the following sections in this review). Information on genetic variances in transporter genes can be obtained from a specialized database for transporter pharmacogenetics established at University of California, San Francisco (http://pharmacogenetics.ucsf.edu/). Clinical genomics also reveal involvement of transporters in bioconversion and toxicity of drugs. One of the most compelling examples of the critical role of transporters in drug toxicity stems from a GWAS encompassing 85 patients with myopathy and 90 normal control individuals (SEARCH Collaborative Group et al., 2008). This study revealed an association between the pathology of myopathy and a SNP within a non-coding region of SLCO1B1 gene. SLCO1B1 encodes the organic 
anion transporting polypeptide (OATP1B1) that has been shown to be involved in the hepatic uptake of statins. GWASs have also associated SLCO1B1 and SLCO1B3 variants with bilirubin levels and unconjugated hyperbilirubinemia (Johnson et al., 2009; Sanna et al., 2009), reflecting the important function of these transporters in the uptake of bilirubin in liver. Other GWASs also showed that variants in SLC01B1 were associated with reduced clearance of methotrexate and thus increased gastrointestinal toxicity (Treviño et al., 2009; Ramsey et al., 2012).

\section{In vitro models}

Analysis of the physiological role(s) of a membrane transporter frequently begins with an in vitro model. Historically, the Xenopus oocyte has been used as a powerful expression system to study transporter activity. Due to the limited expression levels of endogenous membrane transporters, Xenopus oocytes show little background activity, and thus provide reliable information with high signal-to-noise ratio (Bröer, 2010). If combined with high-throughput screening technology, Xenopus oocytes can even serve as a drug screening system for certain transporters (Kvist et al., 2011). Equipment setup for electrophysiology for Xenopus oocytes and efficiency of foreign gene expression, however, are hurdles for its further application. More recently human cell lines, such as HEK-293, CHO and HepaRG cells, have been more widely used as they have metabolism characteristics that are similar to the origin tissues and it is easier to express exogenous transporters in cell lines. Moreover, vectorial transport can be studied in cultured, polarized cells like the Caco-2 and Madin-Darby canine kidney (MDCK) cells. The colon carcinoma cell line Caco-2 are especially useful for the study of intestinal transporters, since these cells exhibit morphological and functional similarity with the enterocytes lining the small intestine (Hidalgo et al., 1989). MDCK cells form a tight monolayer which separates the basolateral and apical sides similar to cells in biological barriers such as the blood-brain barrier and the placenta barrier. Such vectorial transport assays are important when investigating transport across biological barriers, from apical to basolateral side or vice versa.

The primary goal of transporter assays is to determine the kinetics of substrate transport. For the primary active transporter, like the $A B C$ transporter, substrate translocation across the cell membrane is directly correlated to ATP hydrolysis. Thus ATPase assays that measure the inorganic phosphate release using colorimetric measurement can be utilized to assess active transporter kinetics (Glavinas et al., 2007). The ATPase assay is especially useful in highthroughput screening of substrate candidates as well as potent inhibitors. ATPase assays, however, are only useful for a small subset of $A B C$ transporters in which slowly transported substrates do not stimulate detectable ATPase activity. Kinetics analysis for most types of $A B C$ transporters requires whole-cell and vesicle transport assays, as mentioned in the following section.
For non-primary active influx transporters, the kinetics can be measured via uptake assay using intact cells. The accumulation of substrates over a certain period of time can be quantified by radio-isotope scintillation counter or LC/MS. The properties of transporters, however, must be taken into consideration when designing conditions for cellular uptake assays. For proton co-transporters, like those expressed in small intestinal epithelium, optimal transporting activity is usually observed at acidic $\mathrm{pH}$ condition which is close to physiological conditions in the intestine. The proton-coupled folate transporter (PCFT), encoded by SLC46A1, incorporates folate by coupling a proton co-transport down the proton gradient at $\mathrm{pH}$ 5.5 , however, this transport activity is absent at neutral $\mathrm{pH}$ (Nakai et al., 2007). Peptide transporters 1 and 2 (PEPT1 and PEPT2, encoded by SLC15A1 and SLC15A2) are similar examples, which mediate absorption small peptides and peptide-like drugs from the intestine and kidney respectively with symport of a proton (Liu et al., 1995; Liang et al., 1995). There are also examples of sodium symporters whose activity relies on sodium gradient. The transport activity of such transporters, like SLC10A1, SLC10A2, SLC22A4 and SLC34A1, can be greatly suppressed when the sodium ions are replaced by choline (De Bruyn et al., 2011).

Isolated cell membranes are another reliable method to investigate transporter activity. Membranes can be prepared from insect cells, mammalian cell lines, or primary cells in which the transporter of interest is overexpressed. Insect cells like Sf9 and Sf+ are widely used because of high membrane yields and easy culturing. The major drawback of insect cells is that their cholesterol content is significantly lower than that of mammalian cells. Membrane cholesterol contributes to transporter activity, especially in the $A B C$ transporters (ABCB11, Kis et al., 2009; ABCC2, Ito et al., 2008; ABCG2, Pal et al., 2007). Thus supplementation of cholesterol is sometimes necessary when using membranes extracted from insect cells. For efflux transporters, direct measurement of the substrate translocation can be achieved by a vesicular transport assay. Enriched, inside-out membranes are prepared using commercially available kits and incubated with the substrate and ATP or the appropriate energy source for the transporter of interest. After filtration, the vesicles containing the substrates are captured, which allows for quantification of the substrates inside vesicles via radio-isotope scintillation counter or LC/MS.

\section{In vivo models}

To date, mice and rats serve as the most relevant in vivo model for the field of transporter biology. The recent emergence of zinc-finger nuclease (ZFN), TALEN and CRISPR/Cas-based genomic engineering provides powerful and convenient tools to generate transgenic or knockout animals for a gene of interest (Gaj et al., 2013). Beyond traditional overexpression or knockout in the whole body, tissue specific or local modification can also be achieved through floxP-Cre or Tet-on/off expression systems. Moreover, overexpression and knockdown 
locally in a certain tissue or at a specific developmental point can be achieved by microinjection of gene expression vectors followed by electronic transfection. Animal models are a powerful tool to study the physiological function of a transporter. Systemic overexpression or knockdown of a transporter can produce phenotypes that provide information about tissue specific functions. Some transporters are enriched in certain tissues implying that they have unique physiological functions. Thus alteration of transporter activity through genetic means may only be observed locally within a specific tissue and possibly, loss of transporter expression may be compensated by its functional orthologues or homologues. The LC/MS based metabolomics may help characterizations of local metabolite changes caused by transporter deletion or overexpression in a specific tissues or circulating system. For example, tissue extracts from liver or muscle can be used to investigate the role of a transporter in energy related metabolism; urine and serum can be used to study alterations in secreted or excreted metabolites.

\section{DRUG-TRANSPORTER INTERACTIONS}

\section{Drug-drug interactions}

Due to the critical roles of transporters in the ADME of drugs, a variety of drug transporter assays are required by both FDA and EMA prior to testing of a New Chemical/Molecular Entity (NCE/NME). Potential drug-drug interactions (DDIs) may cause severe, adverse reactions in patients due to alteration in ADME by transporters. Most DDIs via transporters involve, but are not restricted to, the main transporters in drug ADME: P-gp, BCRP, OATP1B1/1B3, OAT1/3, OCT1 and OCT2 (Tweedie et al. 2013). The International Transporter Consortium has established decision trees for investigating the transporter interactions of drugs (International Transporter Consortium et al., 2010).

DDIs via a transporter can also occur in an indirect manner. The expression level and transporting activity of transporters may be altered as part of the systemic response (i.e., immune response) to exogenous or endogenous stimuli. Altered drug ADME during inflammation has long been primarily ascribed to changes of enzymes in drug metabolism. An example of this is decreased expression of P450, the main drug metabolizing enzyme in liver, following inflammation. Moreover, recent studies have also shown that the expression and activity of numerous transporters are also changed in inflammatory condition. In experimental cell and animal models, inflammatory conditions induced down regulation of MDRs, MRPs and OATPs. Consequently, the ADME of drugs which are substrates of these transporters would be broadly affected (Petrovic et al., 2007).

\section{Drug-endogenous substrate interactions}

Although DDIs via transporters have been widely studied, the interaction between drugs and endogenous substrates has not received significant attention. The transportation and distribution of many endogenous substrates like hormones, bile acids and neurotransmitters mainly depend on the activity of transporters.

The most well-known case of drug-endogenous substrate interaction is the drug induced liver injury (DILI) due to cholestasis. The transporter BSEP plays an important role in the disposition and exportation of bile salts from liver. BSEP inhibition by drugs can cause accumulation of bile salts in liver, thus leading to cholestasis. There is a strong correlation between inhibition of the in vitro efflux transporter activity of BSEP and the risk of cholestatic DILI (Dawson et al., 2012). BSEP was thought to be the primary bile acid efflux transporter in normal conditions in humans (Kis et al., 2012), while MRP3 and MRP4 may play compensatory roles when BSEP is impaired (Keppler, 2011). A recent study regarding the relationship between MRP3, MRP4 and BSEP inhibition and drugs with cholestatic potential showed that inhibition of MRP4, in addition to BSEP, might be a risk factor for the development of cholestatic DILI, while the inhibition of MRP3 seemed not statistically significantly associated (Köck et al., 2014). The EMA has already included a test of BSEP transporter for potential liver toxicity.

Substrate multi-specificity of transporters and/or low amount of substrates makes altered transport of an endogenous substrate difficult to identify. Local changes in substrate homeostasis, however, may become obvious under pathological conditions. This can be due to the changes of transporter expression level under pathological conditions or because of an individual taking certain drugs. Recently it was reported that the drugs metformin and phenformin competitively inhibited hepatic thiamine uptake via OCT1, a high-capacity thiamine transporter in liver, to modulate the energy status in hepatocytes (Chen et al., 2014). OCT1 is the major hepatic uptake transporter for xenobiotics, including the most prescribed anti-diabetic drug metformin and anti-cancer drug oxilaplatin (Shu et al., 2007; Wang et al., 2002; Li et al., 2011). It has been proposed that together with drug-metabolizing enzymes, OCT1 contributes mainly to the detoxification pathway of liver (Zhang et al., 2006). But the exact physiological role of OCT1 remained speculative. Using metabolomic analysis of OCT1 overexpressed in HEK293 cells and isotopic uptake assays, thiamine was identified as one substrate, with low-affinity but high-capacity to OCT1 (Chen et al., 2014). The Oct1 KO mice provide a model to investigate the function of Oct1 systemically. Thiamine is converted to thiamine monophosphate (TMP) and thiamine pyrophosphate (TPP) in cytosol, which serves as the essential co-enzyme for energy generation and glucose metabolism. Due to reduced thiamine uptake in liver, thiamine-related changes were observed in the serum of Oct1 KO mice. These included reduced levels of TMP and TPP and higher levels of pyruvate and alpha-ketoglutarate, which are the substrates of pyruvate dehydrogenase $(\mathrm{PDH})$ and alpha-ketoglutarate dehydrogenase (OGDH) (Chen et al., 2014), respectively. SLC19A2 (Labay et al., 1999; Diaz et al., 
1999) and SLC19A3 (Rajgopal et al., 2001) are high-affinity thiamine transporters; however, OCT1 is likely the primary transporter for thiamine uptake in the liver. This is supported by the drastic reduction of thiamine uptake in Oct1 deficient mouse primary hepatocytes (Chen et al., 2014). Oct1 deficiency does not lead to obvious outcomes in other tissues where the uptake of thiamine is possibly controlled mainly by SLC19A2 or SLC19A3.

OCT1 has also recently been shown to be a transporter for monoamine neuro-transmitters (serotonin, dopamine, epinephrine and norepinephrine) and OCT1 might play a critical role in the uptake of serotonin in liver (Boxberger et al., 2014). The monoamine uptake transporter SERT is widely expressed in the gut where the monoamine transmitters have important physiological functions. Though liver is the major organ in which serotonin is metabolized, SERT is not expressed in liver (Ramamoorthy et al., 1993). Common OCT1-transported drugs including diphenhydramine, fluoxetine, imatinib and verapamil were shown to inhibit hepatic serotonin uptake with $\mathrm{IC}_{50}$ values in the low micromole range (Boxberger et al., 2014). The reduction of serotonin uptake in Oct1 deficient primary hepatocyte was only $28 \%$ indicating that there are other transporters which contribute to the uptake of serotonin in liver (Chen et al. 2014). OCT3 and PMAT are possibly candidates as both are highcapacity serotonin transporters (Wu et al., 1998; Zhou et al., 2007); however, both have low abundance in the liver compared to OCT1. Another explanation could be that these drugs not only block OCT1 but also other transporters-mediating serotonin uptake in the liver.

The drug-endogenous substrate interaction has also been investigated in the kidney efflux transporters MATEs. Pyrimethamine, a commonly used anti-protozoal drug for both the prevention and treatment of malaria, inhibits the renal clearance of thiamine, carnitine and acylcarnitine by about $80 \%, 90 \%$ and $90 \%$ respectively in urine samples from patients. Nonetheless, plasma concentrations of the aforementioned compounds are not changed. Thus, alterations of thiamine and carnitine in the urine are thought to be useful as biomarkers in evaluating drug interactions via MATEs (Kato et al., 2014).

\section{EMERGING ROLE OF TRANSPORTERS AS THERAPEUTIC TARGETS}

Acting as the "gatekeepers" for the ADME of drugs and endogenous substrates including hormones, glucose, amino acids, inorganic ions, neurotransmitters and cellular metabolites, transporters have drawn increasing attention for drug development in recent years. Transporter-mediated therapeutics is achieved via stimulation or inhibition of the substrate transporting activity or potential cellular signaling involved. More than a dozen transporters have already been targeted in clinical therapy. These include the monoamine transporters for treatment of mental disorders like depression and schizophrenia, SGLT2 for treatment of diabetes and the MDR and MRP transporters in cancer therapy. However, much remains to be uncovered as the physiological functions of many transporters are still largely unknown. The physiological roles of transporters are generally consistent with their distribution in the body, i.e. the tissue specific expression. For example, OCT1 is mainly expressed in the central vein of liver where its physiological function is to uptake thiamine into hepatocytes (Chen et al., 2014). Most of the known functions of transporters involve inward and outward transportation of substrate across the plasma membrane. There are also transporters, however, which localize in the nuclear envelope and membranes of other organelles like the mitochondria, the lysosome, the endoplasmic reticulum and the Golgi apparatus. Investigating the physiological function of transporters is important not only for understanding the nature of substrate transportation but also for the seeking of new therapeutic targets. In this section we discuss three transporters that are potentially involved in the pathology of diabetes as examples of how a transporter's physiological function has therapeutic implications.

\section{The thiamine transporter OCT1}

OCT1 controls the liver uptake of thiamine whose derivative TPP serves as the essential cofactor in energy generation. The loss of Oct1 in mice results in a $70 \%$ reduction in thiamine uptake in liver and significantly reduced fat accumulation in both lean and obese mice. This indicates that OCT1 may be a promising therapeutic target in the treatment of non-alcoholic fatty liver disease for which there are few effective therapies (Halegoua-De Marzio and Fenkel, 2014). Metformin, the most prescribed anti-diabetes drug, inhibits OCT1-mediated thiamine uptake, which corresponds well to the physiological role of OCT1 (Chen et al., 2014). This finding not only uncovered part of the pharmacological effect of metformin but also provides new therapeutic insight in the treatment of diabetes. An intriguing possibility is that by regulating the uptake of thiamine by hepatocytes, it is possible to alter the energy status in the liver and thus regulate the homeostasis of gluconeogenesis and glycolysis in diabetic patients.

\section{The citrate transporter SLC13A5}

In Drosophila, loss of INDY (I'm Not Dead Yet), the homologue of mammal SLC13A5, confers extended lifespan in a caloric restriction-like manner (Rogina et al., 2000) with reduced whole body fat stores and expression of insulin like proteins (Wang et al., 2009). SLC13A5 mediates the uptake of citrate into cytosol across the plasma membrane with high specificity. Analyses of the structure of bacterial Indy reveal a conserved substrate binding region across a wide range of species (Mancusso et al., 2012). As one of the main intermediates in the TCA cycle, citrate also regulates fatty acid synthesis and $\beta$ oxidation (Fig. 1). Hence, SLC13A5 may serve as a potential therapeutic target in the treatment of metabolic disorders 


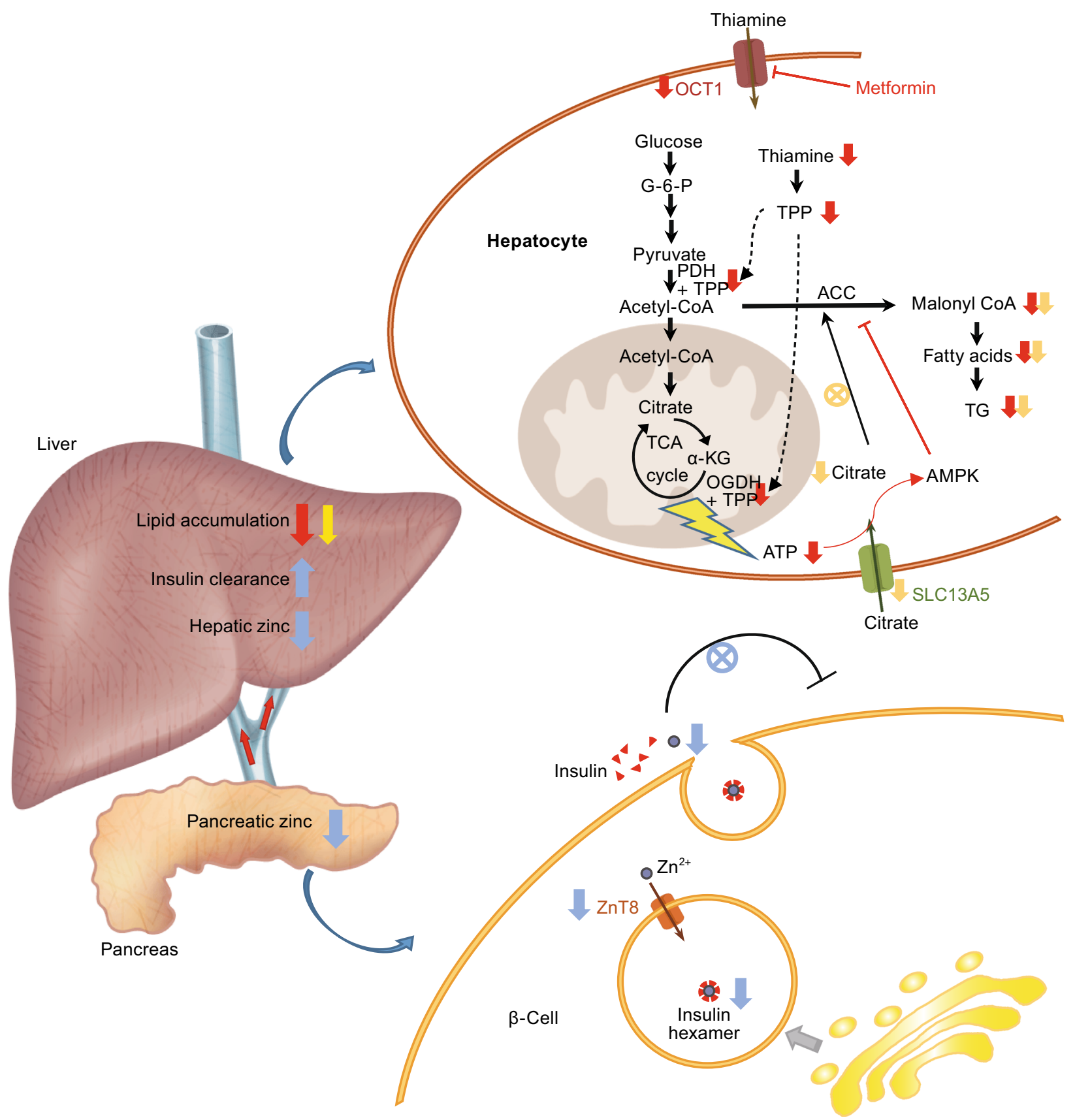

Figure 1. Cartoon illustration of the physiological roles and therapeutic implications of OCT1, SLC13A5 and ZnT8 in glucose metabolism, lipogenesis and insulin pathway. Inhibition of OCT1 (e.g., metformin treatment) results in lowered hepatic thiamine uptake, and consequently reduced TPP levels. The reduced ATP production, due to the decreased PDH and OGDH activity, triggers AMPK activation. The inhibition of SLC13A5 leads to lowered cytosol citrate contents, which attenuate the activating effect of citrate in malonyl-CoA synthesis. Both OCT1 and SLC13A5 inhibition reduce TG synthesis in the liver. Inhibition of ZnT8 causes reduced zinc release from the $\beta$-cell, and thus attenuates the autocrine effect of zinc in glucose induced insulin production; the hepatic zinc content is also reduced, with concomitant increased insulin clearance. The effects of OCT1, SLC13A5 and ZnT8 inhibition are shown with red, yellow and blue arrows respectively.

including non-alcoholic fatty liver disease, obesity and diabetes. Consistent with this, loss of S/c13a5 in mice results in reduction in the liver uptake of citrate from circulation accompanied by an increase in mitochondrial biogenesis, lipid oxidation, energy expenditure and decrease in hepatic de novo lipogenesis. The loss of S/c13a5 also protects mice from 
high-fat diet induced obesity and insulin resistance (Birkenfeld et al., 2011). Currently, there is no available drug that specifically modulates SLC13A5 activity. Some compounds have been reported as selective inhibitors of the plasma membrane citrate transporter for both mammalian SLC13A5 and the Drosophila INDY, leaving mitochondria citrate transporter activity unchanged (Sun et al., 2010). A recent study reported the crystal structure of VcINDY, a homologue of SLC13A5 in Vibrio cholera at $3.20 \AA$. This provides the structural basis for understanding the substrate binding properties as well as conformational change upon substrate binding (Mulligan et al., 2014). Together with computational biology, the development of drugs targeting the SLC13A5 could be accelerated for potential therapeutics of carbohydrate and lipid metabolism disorders like diabetes, non-alcoholic fatty liver and obesity.

\section{Zinc transporter ZnT8}

Zinc transporters are reported to be involved in the pathophysiology of cancer, cardiovascular diseases and Alzheimer's disease making them possible therapeutic targets for treatment of these diseases (Prasad et al., 2009; Little et al., 2010; Watt et al., 2011). Normal cellular function requires tightly controlled zinc homeostasis through coordinated actions of zinc transporters and metallothioneins. Emerging evidences suggest that zinc transporters are also involved in that pathology of diabetes mellitus. Zinc plays key roles in the synthesis, storage and secretion of insulin in response to elevated glucose concentrations (Mocchegiani et al., 2008; Wijesekara et al., 2009). Of particular relevance to diabetes is the most well studied zinc transporter ZnT8 (SLC30A8). $\mathrm{ZnT8}$ is responsible for the packaging and storage of insulin as $\mathrm{Zn}^{2+}$-insulin hexamers in the secretory granules of the pancreas, which releases the physiologically active form of insulin in the serum driven by a pH change (Xu et al., 2012b). The relationship between $\mathrm{ZnT} 8$ and diabetes risk has been verified in cultured cells as well as in mice. In a pancreatic cell line INS-1, ZnT8 overexpression showed enhanced glucose-stimulated insulin secretion (Chimienti et al., 2006) while down regulation of this transporter leads to reduced insulin production in response to a hyperglycemic stimulus (Fu et al., 2009). Knockout mice with global deficiency of ZnT8 showed normal glucose homeostasis and insulin production under normal conditions (Lemaire et al., 2009). Glucose tolerance and glucose-induced insulin secretion are impaired when challenged with a high-fat diet and these mice further develop diabetic obesity and insulin resistance (Lemaire et al., 2009; Nicolson et al., 2009). Mutant mice with a targeted beta cell ZnT8 deficiency display glucoseintolerance, reduced beta cell zinc accumulation and increased proinsulin levels when fed with high-fat diet, indicating the deficiency in insulin processing and secretion. These mice, however, do not develop obesity (Wijesekara et al., 2010). Genetic studies in humans also support a correlation between ZnT8 and diabetes risk. Several
GWASs revealed genetic association between ZnT8 and diabetes onset (Sladek et al., 2007; Xu et al., 2012a; Diabetes Genetics Initiative et al., 2007). The most compelling evidence comes from a common SNP rs13266634 (c.973T>A, p.Trp325Arg) in Europeans which increased the risk of developing type II diabetes with concomitant impaired conversion of proinsulin to insulin (Sladek et al., 2007 and Kirchhoff et al., 2008). Cellular experiments show that the Arg325 ZnT8 variant exhibits lower apparent $\mathrm{Zn}^{2+}$ transport activity than the Trp325 ZnT8 (Nicolson et al., 2009). Collectively these studies indicated that reduced $\mathrm{Zn}$ transport activity by $\mathrm{ZnT8}$ is connected to the diabetes risk. Thus treatments that increase ZnT8 transport activity might be a novel therapeutic route for treatment of diabetes.

The exact relationship between ZnT8 activity and diabetes risk, however, remains controversial. $\mathrm{Zn}$ ions have several effects on the regulation of insulin production and clearance. Co-secretion of $\mathrm{Zn}$ ions with insulin from beta cells inhibits insulin production in an autocrine and paracrine fashion through the K-ATP channel (Bancila et al., 2005; Prost et al., 2004). Beta cell-secreted $\mathrm{Zn}$ ions also regulate hepatic clearance of insulin. A recent study showed that beta-cell specific deficiency of $\mathrm{ZnT8}$ results in low peripheral insulin level but hypersecretion of insulin from pancreas (Tamaki et al., 2013). Further, ZnT8 deficient mice and humans with the Trp325Arg ZnT8 variant exhibit increased insulin clearance. This in turn stimulates the secretion of insulin by pancreas and increases susceptibility to developing type II diabetes (Tamaki et al., 2013).

Intriguingly, a recent GWAS reported that 12 , rare truncating mutations in ZnT8 were surprisingly protective against developing diabetes and, collectively, explained a $65 \%$ reduction in diabetes risk (Flannick et al., 2014). Although their study was originally performed in the European population with SNP rs13266634 genetic background, it was shown that this haplotypic background did not influence the conclusion (Flannick et al., 2014). Though the exact mechanism remains elusive, the size of the GWAS data pool $(\sim 150,000$ individuals across five ancestry groups) legitimizes the finding. A recent review of the paper pointed to the unclear association between increased insulin receptor binding and liver insulin action with lower concentration of $\mathrm{Zn}$ ions (Pearson, 2014). Clearly, the roles of ZnT8 in Zn homeostasis and diabetes are more complicated than expected. On the one hand, ZnT8 is essential for insulin processing and secretion in response to glucose challenge thus total loss of its function causes glucose-intolerance. On the other, secreted Zinc ions into liver portal vein indeed regulate the gluconeogenesis and insulin pathway in hepatocytes. The GWAS by Flannick et al. reveals an alternate view of ZnT8 and diabetes risk. Different from OCT1 and SLC13A5, which show local control of carbohydrate and lipid metabolism in the hepatocytes, ZnT8 shows a systemic regulation of insulin pathway in the pancreas and liver (Fig. 1). Thus, drug candidates that act on ZnT8 would be expected to be potent novel anti-diabetes therapeutics. 


\section{SUMMARY AND FUTURE PERSPECTIVES}

Transporter biology is a rapidly changing field in pharmaceutical research. Identifying the function of transporters in physiological and pathological conditions is garnering significant attention for drug development. Many drugs, nutrients and metabolites are moved by transporters not only through the plasma membrane but also among subcellular organelles like vesicles, ER, lysosome and mitochondria. Transporters remain one of the most underestimated fields for drug targets. Within the hundreds of annotated transporters in human genome, more than half are orphan transporters with unknown substrates or function. The nature of these transporters, including their expression and localization in organs and tissues, subcellular localization, endogenous substrates, largely remains elusive. As discussed in this review, transporters can be of significant therapeutic potential in the treatment of various diseases. A comprehensive dissection of the physiological roles of the transporter could be a key step to excavate this "gold mine". Our growing knowledge of transporter biology will greatly accelerate the discovery of novel drug targets and development of first-in-class therapies.

\section{ACKNOWLEDGEMENTS}

We are very grateful to Dr. Julie Siegenthaler in University of Colorado at Denver for critically reading the manuscript and making many helpful suggestions. We thank Mr. Kun Sun from our laboratory on the figure drawing and editing. This work is supported by National 1000-Talent Program (No. 20141770980), the National Natural Science Foundation of China (Grant No. 041322006) and a starting fund from Tsinghua-Peking Joint Center for Life Sciences.

\section{ABBREVIATIONS}

ABC, ATP binding cassette; ADME, absorption, distribution, metabolism and elimination; DDI, drug-drug interaction; DILI, drug induced liver injury; GABA, $y$-aminobutyric acid; GAT, GABA transporter; GWAS, genome wide association study; HTS, highthroughput screening; INDY, I'm Not Dead Yet; LAT, large-neutral amino acid transporter; LC/MS, liquid chromatography/mass spectrometry; MATE, multidrug and toxin extrusion transporter; NET, norepinephrine transporter; OGDH, oxoglutarate (alpha-ketoglutarate) dehydrogenase alpha-ketoglutarate dehydrogenase; $\mathrm{PDH}$, pyruvate dehydrogenase; QSAR, quantitative structure-activity relationship; SLC, solute carrier; SNP, single nucleotide polymorphism; TMP, thiamine monophosphate; TPP, thiamine pyrophosphate.

\section{COMPLIANCE WITH ETHICS GUIDELINES}

Yu Liang, Siqi Li and Ligong Chen declare that they have no conflict of interest.

\section{OPEN ACCESS}

This article is distributed under the terms of the Creative Commons Attribution License which permits any use, distribution, and reproduction in any medium, provided the original author(s) and the source are credited.

\section{REFERENCES}

Alper SL, Sharma AK (2013) The SLC26 gene family of anion transporters and channels. Mol Asp Med 34:494-515

Bancila V, Cens T, Monnier D, Chanson F, Faure C, Dunant Y, Bloc A (2005) Two SUR1-specific histidine residues mandatory for zincinduced activation of the rat KATP channel. J Biol Chem 280:8793-8799

Birkenfeld AL, Lee HY, Guebre-Egziabher F, Alves TC, Jurczak MJ, Jornayvaz FR, Zhang D, Hsiao JJ, Martin-Montalvo A, FischerRosinsky A et al (2011) Deletion of the mammalian INDY homologue mimics aspects of dietary restriction and protects against adiposity and insulin resistance in mice. Cell Metab 14:184-195

Boxberger KH, Hagenbuch B, Lampe JN (2014) Common drugs inhibit human organic cation transporter 1 (OCT1)-mediated neurotransmitter uptake. Drug Metab Dispos 42:990-995

Bröer S (2010) Xenopus laevis Oocytes. Methods Mol Biol 637:295310

Chen L, Shu Y, Liang X, Chen EC, Yee SW, Zur AA, Li S, Xu L, Keshari KR, Lin MJ et al (2014) OCT1 is a high-capacity thiamine transporter that regulates hepatic steatosis and is a target of metformin. Proc Natl Acad Sci USA 111:9983-9988

Chimienti F, Devergnas S, Pattou F, Schuit F, Garcia-Cuenca R, Vandewalle B, Kerr-Conte J, Van Lommel L, Grunwald D, Favier A et al (2006) In vivo expression and functional characterization of the zinc transporter ZnT8 in glucose-induced insulin secretion. J Cell Sci 119:4199-4206

Dawson S, Stahl S, Paul N, Barber J, Kenna JG (2012) In vitro inhibition of the bile salt export pump correlates with risk of cholestatic drug-induced liver injury in humans. Drug Metab Dispos 40:130-138

De Bruyn T, Ye ZW, Peeters A, Sahi J, Baes M, Augustijns PF, Annaert PP (2011) Determination of OATP-, NTCP- and OCTmediated substrate uptake activities in individual and pooled batches of cryopreserved human hepatocytes. Eur J Pharm Sci 43:297-307

Deng D, Xu C, Sun P, Wu J, Yan C, Hu M, Yan N (2014) Crystal structure of the human glucose transporter GLUT1. Nature 510:121-125

Diabetes Genetics Initiative of Broad Institute of Harvard and Mit, Lund University, Novartis Institutes of BioMedical Research, Saxena R, Voight BF, Lyssenko V, Burtt NP, de Bakker PI, Chen $\mathrm{H}$, Roix JJ et al (2007) Genome-wide association analysis identifies loci for type 2 diabetes and triglyceride levels. Science 316:1331-1336

Diaz GA, Banikazemi M, Oishi K, Desnick RJ, Gelb BD (1999) Mutations in a new gene encoding a thiamine transporter cause thiamine-responsive megaloblastic anaemia syndrome. Nat Genet 22:309-312

Fang $Y$, Jayaram $H$, Shane $T$, Kolmakova-Partensky L, Wu F, Williams C, Xiong Y, Miller C (2009) Structure of a prokaryotic virtual proton pump at 3.2 A resolution. Nature 460:1040-1043

Flannick J, Thorleifsson G, Beer NL, Jacobs SB, Grarup N, Burtt NP, Mahajan A, Fuchsberger C, Atzmon G, Benediktsson R et al (2014) Loss-of-function mutations in SLC30A8 protect against type 2 diabetes. Nat Genet 46:357-363 
Fu Y, Tian W, Pratt EB, Dirling LB, Shyng SL, Meshul CK, Cohen DM (2009) Down-regulation of ZnT8 expression in INS-1 rat pancreatic beta cells reduces insulin content and glucose-inducible insulin secretion. PLoS One 4:e5679

Gáborík Z, Grindstaff K, Oosterbuis B (2014) Experts only-the transporter book. SOLVO Biotechnology, Budaörs

Gaj T, Gersbach CA, Barbas CF 3rd (2013) ZFN, TALEN, and CRISPR/Cas-based methods for genome engineering. Trends Biotechnol 31:397-405

Gao X, Lu F, Zhou L, Dang S, Sun L, Li X, Wang J, Shi Y (2009) Structure and mechanism of an amino acid antiporter. Science 324:1565-1568

Geier EG, Schlessinger A, Fan H, Gable JE, Irwin JJ, Sali A, Giacominia KM (2013) Structure-based ligand discovery for the large-neutral amino acid transporter 1, LAT-1. Proc Natl Acad Sci USA 110:5480-5485

Glavinas H, Kis E, Pal A, Kovacs R, Jani M, Vagi E, Molnar E, Bansaghi S, Kele Z, Janaky T et al (2007) ABCG2 (breast cancer resistance protein/mitoxantrone resistance-associated protein) ATPase assay: a useful tool to detect drug-transporter interactions. Drug Metab Dispos 35:1533-1542

Gottesman MM, Ambudkar SV (2001) Overview: ABC transporters and human disease. J Bioenerg Biomembr 33:453-458

Grisanzio C, Werner L, Takeda D, Awoyemi BC, Pomerantz MM, Yamada H, Sooriakumaran P, Robinson BD, Leung R, Schinzel $A C$ et al (2012) Genetic and functional analyses implicate the NUDT11, HNF1B, and SLC22A3 genes in prostate cancer pathogenesis. Proc Natl Acad Sci USA 109:11252-11257

Gründemann D, Harlfinger S, Golz S, Geerts A, Lazar A, Berkels R, Jung N, Rubbert A, Schomig E (2005) Discovery of the ergothioneine transporter. Proc Natl Acad Sci USA 102:52565261

Gruswitz F, Chaudhary S, Ho JD, Schlessinger A, Pezeshki B, Ho CM, Sali A, Westhoff CM, Stroud RM (2010) Function of human Rh based on structure of RhCG at 2.1 A. Proc Natl Acad Sci USA 107:9638-9643

Hagenbuch B, Stieger B (2013) The SLCO (former SLC21) superfamily of transporters. Mol Asp Med 34:396-412

Halegoua-De Marzio DL, Fenkel JM (2014) Concepts and treatment approaches in nonalcoholic fatty liver disease. Adv Hepatol, Article ID 357965

Hidalgo IJ, Raub TJ, Borchardt RT (1989) Characterization of the human colon carcinoma cell line (Caco-2) as a model system for intestinal epithelial permeability. Gastroenterology 96:736-749

International Transporter Consortium, Giacomini KM, Huang SM, Tweedie DJ, Benet LZ, Brouwer KL, Chu X, Dahlin A, Evers R, Fischer $V$ et al (2010) Membrane transporters in drug development. Nat Rev Drug Discov 9:215-236

Ito K, Hoekstra D, van ljzendoorn SC (2008) Cholesterol but not association with detergent resistant membranes is necessary for the transport function of MRP2/ABCC2. FEBS Lett 582:41534157

Johnson AD, Kavousi M, Smith AV, Chen MH, Dehghan A, Aspelund T, Lin JP, van Duijn CM, Harris TB, Cupples LA et al (2009) Genome-wide association meta-analysis for total serum bilirubin levels. Hum Mol Genet 18:2700-2710
Kato K, Mori H, Kito T, Yokochi M, Ito S, Inoue K, Yonezawa A, Katsura T, Kumagai $\mathrm{Y}$, Yuasa $\mathrm{H}$ et al (2014) Investigation of endogenous compounds for assessing the drug interactions in the urinary excretion involving multidrug and toxin extrusion proteins. Pharm Res 31:136-147

Keppler D (2011) Cholestasis and the role of basolateral efflux pumps. Z Gastroenterol 49:1553-1557

Kirchhoff K, Machicao F, Haupt A, Schafer SA, Tschritter O, Staiger $\mathrm{H}$, Stefan N, Haring HU, Fritsche A (2008) Polymorphisms in the TCF7L2, CDKAL1 and SLC30A8 genes are associated with impaired proinsulin conversion. Diabetologia 51:597-601

Kis E, loja E, Nagy T, Szente L, Heredi-Szabo K, Krajcsi P (2009) Effect of membrane cholesterol on BSEP/Bsep activity: species specificity studies for substrates and inhibitors. Drug Metab Dispos 37:1878-1886

Kis E, loja E, Rajnai Z, Jani M, Mehn D, Heredi-Szabo K, Krajcsi P (2012) BSEP inhibition: in vitro screens to assess cholestatic potential of drugs. Toxicol In Vitro 26:1294-1299

Köck K, Ferslew BC, Netterberg I, Yang K, Urban TJ, Swaan PW, Stewart PW, Brouwer KL (2014) Risk factors for development of cholestatic drug-induced liver injury: inhibition of hepatic basolateral bile acid transporters multidrug resistance-associated proteins 3 and 4. Drug Metab Dispos 42:665-674

Koepsell H (2013) The SLC22 family with transporters of organic cations, anions and zwitterions. Mol Asp Med 34:413-435

Kvist T, Hansen KB, Bräuner-Osborne H (2011) The use of Xenopus oocytes in drug screening. Expert Opin Drug Discov 6:141-153

Labay V, Raz T, Baron D, Mandel H, Williams H, Barrett T, Szargel R, McDonald L, Shalata A, Nosaka K et al (1999) Mutations in SLC19A2 cause thiamine-responsive megaloblastic anaemia associated with diabetes mellitus and deafness. Nat Genet 22:300-304

Lemaire K, Ravier MA, Schraenen A, Creemers JW, Van de Plas R, Granvik M, Van Lommel L, Waelkens E, Chimienti F, Rutter GA et al (2009) Insulin crystallization depends on zinc transporter ZnT8 expression, but is not required for normal glucose homeostasis in mice. Proc Natl Acad Sci USA 106:14872-14877

Li S, Chen Y, Zhang S, More SS, Huang X, Giacomini KM (2011) Role of organic cation transporter 1, OCT1 in the pharmacokinetics and toxicity of cis-diammine(pyridine)chloroplatinum(II) and oxaliplatin in mice. Pharm Res 28:610-625

Liang R, Fei YJ, Prasad PD, Ramamoorthy S, Han H, Yang-Feng TL, Hediger MA, Ganapathy V, Leibach FH (1995) Human intestinal $\mathrm{H}+$ /peptide cotransporter. Cloning, functional expression, and chromosomal localization. J Biol Chem 270:6456-6463

Little PJ, Bhattacharya R, Moreyra AE, Korichneva IL (2010) Zinc and cardiovascular disease. Nutrition 26:1050-1057

Liu W, Liang R, Ramamoorthy S, Fei YJ, Ganapathy ME, Hediger MA, Ganapathy V, Leibach FH (1995) Molecular cloning of PEPT 2, a new member of the $\mathrm{H}+$ /peptide cotransporter family, from human kidney. Biochim Biophys Acta 1235:1235-1466

Lu F, Li S, Jiang Y, Jiang J, Fan H, Lu G, Deng D, Dang S, Zhang X, Wang $J$ et al (2011) Structure and mechanism of the uracil transporter UraA. Nature 472:243-246

Mancusso R, Gregorio GG, Liu Q, Wang DN (2012) Structure and mechanism of a bacterial sodium-dependent dicarboxylate transporter. Nature 491:622-626 
Mizuno N, Niwa T, Yotsumoto Y, Sugiyama Y (2003) Impact of drug transporter studies on drug discovery and development. Pharmacol Rev 55:425-461

Mocchegiani E, Giacconi R, Malavolta M (2008) Zinc signalling and subcellular distribution: emerging targets in type 2 diabetes. Trends Mol Med 14:419-428

Mulligan C, Fitzgerald GA, Wang DN, Mindell JA (2014) Functional characterization of a $\mathrm{Na}$-dependent dicarboxylate transporter from Vibrio cholerae. J Gen Physiol 143:745-759

Nakai $\mathrm{Y}$, Inoue K, Abe N, Hatakeyama M, Ohta KY, Otagiri M, Hayashi Y, Yuasa H (2007) Functional characterization of human proton-coupled folate transporter/heme carrier protein 1 heterologously expressed in mammalian cells as a folate transporter. J Pharmacol Exp Ther 322:469-476

Nakayama A, Matsuo H, Takada T, Ichida K, Nakamura T, Ikebuchi Y, Ito K, Hosoya T, Kanai Y, Suzuki $H$ et al (2011) ABCG2 is a high-capacity urate transporter and its genetic impairment increases serum uric acid levels in humans. Nucleosides Nucleotides Nucleic Acids 30:1091-1097

Nicolson TJ, Bellomo EA, Wijesekara N, Loder MK, Baldwin JM, Gyulkhandanyan AV, Koshkin V, Tarasov Al, Carzaniga R, Kronenberger $\mathrm{K}$ et al (2009) Insulin storage and glucose homeostasis in mice null for the granule zinc transporter ZnT8 and studies of the type 2 diabetes-associated variants. Diabetes 58:2070-2083

Pal A, Mehn D, Molnar E, Gedey S, Meszaros P, Nagy T, Glavinas H, Janaky T, von Richter O, Bathori $G$ et al (2007) Cholesterol potentiates ABCG2 activity in a heterologous expression system: improved in vitro model to study function of human ABCG2. J Pharmacol Exp Ther 321:1085-1094

Pascual JM, Wang D, Lecumberri B, Yang H, Mao X, Yang R, De Vivo DC (2004) GLUT1 deficiency and other glucose transporter diseases. Eur J Endocrinol 150:627-633

Pearson E (2014) Zinc transport and diabetes risk. Nat Genet 46:323-324

Petrovic V, Teng S, Piquette-Miller M (2007) Regulation of drug transporters during infection and inflammation. Mol Interv 7:99111

Prasad AS, Beck FW, Snell DC, Kucuk O (2009) Zinc in cancer prevention. Nutr Cancer 61:879-887

Prost AL, Bloc A, Hussy N, Derand R, Vivaudou M (2004) Zinc is both an intracellular and extracellular regulator of KATP channel function. J Physiol 15:157-167

Rajgopal A, Edmondnson A, Goldman ID, Zhao R (2001) SLC19A3 encodes a second thiamine transporter ThTr2. Biochim Biophys Acta 1537:175-178

Ramamoorthy S, Bauman AL, Moore KR, Han H, Yang-Feng T, Chang AS, Ganapathy V, Blakely RD (1993) Antidepressant- and cocaine-sensitive human serotonin transporter: molecular cloning, expression, and chromosomal localization. Proc Natl Acad Sci USA 90:2542-2546

Ramsey LB, Bruun GH, Yang W, Treviño LR, Vattathil S, Scheet P, Cheng C, Rosner GL, Giacomini KM, Fan Y et al (2012) Rare versus common variants in pharmacogenetics: SLCO1B1 variation and methotrexate disposition. Genome Res 22:1-8

Rappaport N, Nativ N, Stelzer G, Twik M, Guan-Golan Y, Stein TI, Bahir I, Belinky F, Morrey CP, Safran M, et al (2013) MalaCards: an integrated compendium for diseases and their annotation. Database 2013: bat018.

Rogina B, Reenan RA, Nilsen SP, Helfand SL (2000) Extended lifespan conferred by cotransporter gene mutations in Drosophila. Science 290:2137-2140

Sanna S, Busonero F, Maschio A, McArdle PF, Usala G, Dei M, Lai S, Mulas A, Piras MG, Perseu L et al (2009) Common variants in the SLCO1B3 locus are associated with bilirubin levels and unconjugated hyperbilirubinemia. Hum Mol Genet 18:2711-2718

Schlessinger A, Geier E, Fan H, Irwin JJ, Shoichet BK, Giacomini KM, Sali A (2011) Structure-based discovery of prescription drugs that interact with the norepinephrine transporter, NET. Proc Natl Acad Sci USA 108:15810-15815

Schlessinger A, Wittwer MB, Dahlin A, Khuri N, Bonomi M, Fan H, Giacomini KM, Sali A (2012) High selectivity of the $\gamma$-aminobutyric acid transporter 2 (GAT-2, SLC6A13) revealed by structurebased approach. J Biol Chem 287:37745-37756

SEARCH Collaborative Group, Link E, Parish S, Armitage J, Bowman L, Heath S, Matsuda F, Gut I, Lathrop M, Collins R (2008) SLCO1B1 variants and statin-induced myopathy-a genomewide study. N Engl J Med 359:789-799

Shaffer PL, Goehring A, Shankaranarayanan A, Gouaux E (2009) Structure and mechanism of a na+-independent amino acid transporter. Science 325:1010-1014

Shu Y, Sheardown SA, Brown C, Owen RP, Zhang S, Castro RA, lanculescu AG, Yue L, Lo JC, Burchard EG et al (2007) Effect of genetic variation in the organic cation transporter 1 (OCT1) on metformin action. J Clin Invest 117:1422-1431

Sladek R, Rocheleau G, Rung J, Dina C, Shen L, Serre D, Boutin P, Vincent D, Belisle A, Hadjadj $S$ et al (2007) A genome-wide association study identifies novel risk loci for type 2 diabetes. Nature 445:881-885

Stefková J, Poledne R, Hubacek JA (2004) ATP-binding cassette $(A B C)$ transporters in human metabolism and diseases. Physiol Res 53:235-243

Suhre K, Shin SY, Petersen AK, Mohney RP, Meredith D, Wägele B, Altmaier E, Cardiogram Deloukas, Erdmann PJ et al (2011) Human metabolic individuality in biomedical and pharmaceutical research. Nature 477:54-60

Sun J, Aluvila S, Kotaria R, Mayor JA, Walters DE, Kaplan RS (2010) Mitochondrial and plasma membrane citrate transporters: discovery of selective inhibitors and application to structure/function analysis. Mol Cell Pharmacol 2:101-110

Tamaki M, Fujitani Y, Hara A, Uchida T, Tamura Y, Takeno K, Kawaguchi M, Watanabe T, Ogihara T, Fukunaka A et al (2013) The diabetes-susceptible gene SLC30A8/ZnT8 regulates hepatic insulin clearance. J Clin Invest 123:4513-4524

Treviño LR, Shimasaki N, Yang W, Panetta JC, Cheng C, Pei D, Chan D, Sparreboom A, Giacomini KM, Pui CH et al (2009) Germline genetic variation in an organic anion transporter polypeptide associated with methotrexate pharmacokinetics and clinical effects. J Clin Oncol 27:5972-5978

Tweedie D, Polli JW, Berglund EG, Huang SM, Zhang L, Poirier A, Chu X, Feng B, International Transporter, C (2013) Transporter studies in drug development: experience to date and follow-up on decision trees from the international transporter consortium. Clin Pharmacol Ther 94:113-125 
Wang DS, Jonker JW, Kato Y, Kusuhara H, Schinkel AH, Sugiyama $Y(2002)$ Involvement of organic cation transporter 1 in hepatic and intestinal distribution of metformin. J Pharmacol Exp Ther 302:510-515

Wang PY, Neretti N, Whitaker R, Hosier S, Chang C, Lu D, Rogina B, Helfand SL (2009) Long-lived Indy and calorie restriction interact to extend life span. Proc Natl Acad Sci USA 106:9262-9267

Watt NT, Whitehouse IJ, Hooper NM (2011) The role of zinc in alzheimer's disease. Int J Alzheimer's Dis. Article ID 971021.

Wijesekara N, Chimienti F, Wheeler MB (2009) Zinc, a regulator of islet function and glucose homeostasis. Diabetes Obes Metab 11 (Suppl 4):202-214

Wijesekara N, Dai FF, Hardy AB, Giglou PR, Bhattacharjee A, Koshkin V, Chimienti F, Gaisano HY, Rutter GA, Wheeler MB (2010) Beta cell-specific Znt8 deletion in mice causes marked defects in insulin processing, crystallisation and secretion. Diabetologia 53:1656-1668

Wittwer MB, Zur AA, Khuri N, Kido Y, Kosaka A, Zhang X, Morrissey KM, Sali A, Huang Y, Giacomini KM (2013) Discovery of potent, selective multidrug and toxin extrusion transporter 1 (MATE1, SLC47A1) inhibitors through prescription drug profiling and computational modeling. J Med Chem 56:781-795
Woodward OM, Kottgen A, Coresh J, Boerwinkle E, Guggino WB, Kottgen M (2009) Identification of a urate transporter, ABCG2, with a common functional polymorphism causing gout. Proc Natl Acad Sci USA 106:10338-10342

Wu X, Kekuda R, Huang W, Fei YJ, Leibach FH, Chen J, Conway SJ, Ganapathy V (1998) Identity of the organic cation transporter OCT3 as the extraneuronal monoamine transporter (uptake2) and evidence for the expression of the transporter in the brain. J Biol Chem 273:32776-32786

Xu J, Wang J, Chen B (2012a) SLC30A8 (ZnT8) variations and type 2 diabetes in the Chinese Han population. Genet Mol Res 11:1592-1598

Xu Y, Yan Y, Seeman D, Sun L, Dubin PL (2012b) Multimerization and aggregation of native-state insulin: effect of zinc. Langmuir 28:579-586

Zhang L, Strong JM, Qu W, Lesko LJ, Huang SM (2006) Scientific perspectives on drug transporters and their role in drug interactions. Mol Pharm 3:62-69

Zhou M, Engel K, Wang J (2007) Evidence for significant contribution of a newly identified monoamine transporter (PMAT) to serotonin uptake in the human brain. Biochem Pharmacol 1:147154 